\title{
A CONTRIBUTION TO THE DEVELOPMENT OF THE PERICARDIUM ${ }^{1}$
}

\author{
RUSH ELLIOTT \\ Department of Anatomy, University of Michigan ${ }^{2}$
}

SEVENTEEN FIGURES

CONTENTS

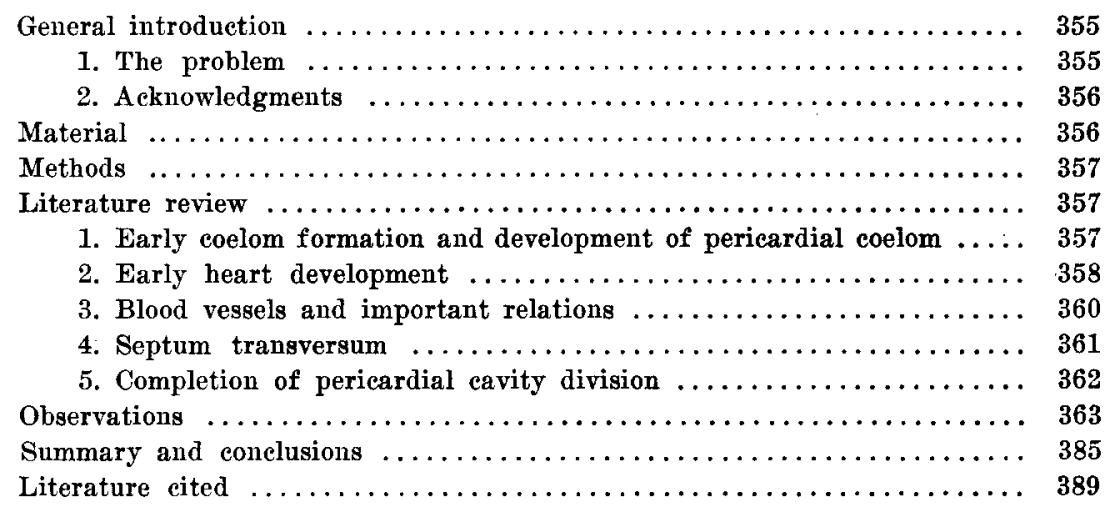

GENERAL INTRODUCTION

1. The problem

The problem under investigation in the present work is one concerning which considerable anatomic literature is to be found, but a consideration of the facts given shows many disagreements in explanations and interpretations, so that further investigation seems justified.

This problem involves a reinvestigation of the early formation of the coelom as a single cavity and the subsequent formation of the pericardium which separates the pericardial and pleural cavities, and the production of reconstructions to demonstrate the formation of these cavities.

${ }^{1}$ From a dissertation submitted in partial fulfillment of the requirement for the degree of Doctor of Philosophy in the University of Michigan.

${ }^{2}$ At present assistant professor of biology, Ohio University. 


\section{Acknowledgments}

The author is indebted to Prof. G. Carl Huber for his kindness in placing the material for this investigation at his disposal, for directing the investigation, and for encouragement during the course of the work.

I wish also to acknowledge the kind assistance of Mr. Leroy $J$. Smith in the preparation of the wax plates used in the reconstructions.

I am also grateful for financial assistance given by the University of Michigan in the form of a Graduate School Fellowship, which I was privileged to hold during the school years of 1928-29 and 1929-30.

\section{MATERIAL}

The material for this problem consists of rabbit embryos (Lepus cuniculus) which were prepared by Doctor Huber and are found in the collection of embryological material of the Department of Anatomy, University of Michigan. These series of embryos were prepared by fixation in Zenker's, Carnoy's, and Bouin's fluids and cut in sagittal and crosssections. The following table will give the fundamental information regarding the series employed in the present investigation.

\begin{tabular}{|c|c|c|c|c|c|}
\hline $\begin{array}{l}\text { No. OF } \\
\text { EMBRYO }\end{array}$ & $\begin{array}{l}\text { AGE FROM } \\
\text { INSEMINA- } \\
\text { TION, DAYS } \\
\end{array}$ & $\begin{array}{c}\text { PROBABLE } \\
\text { LENGTH } \\
\text { (AVERAGE) } \\
\text { MAM. } \\
\end{array}$ & $\begin{array}{l}\text { PLANE OF } \\
\text { SECTION }\end{array}$ & $\begin{array}{l}\text { THIOKNESS OF } \\
\text { SEOTION }\end{array}$ & $\begin{array}{c}\text { SECTIONS IN } \\
\text { EMBRYONIC } \\
\text { SHIELD } \\
\end{array}$ \\
\hline 1 & 9 & 3.5 & Cross & $10 \mu$ & 199 \\
\hline 2 & 9 & 3.5 & Cross & $10 \mu$ & 270 \\
\hline 3 & 9 & 3.5 & Cross & $10 \mu$ & 224 \\
\hline 4 & 9 & 3.5 & Cross & $10 \mu$ & 222 \\
\hline 5 & 9 & 3.5 & Sagittal & $10 \mu$ & 99 \\
\hline 6 & 9 & 3.5 & Sagittal & $10 \mu$ & $\begin{array}{c}81 \\
\text { (sections used in } \\
\text { reconstruction) }\end{array}$ \\
\hline 7 & 10 & 3.6 & Cross & $3 \mu$ & 83 \\
\hline 8 & 10 & 3.6 & Sagittal & $5 \mu$ & 83 \\
\hline 9 & 11 & 5.0 & Sagittal & $3 \mu$ & 122 \\
\hline 10 & 12 & 5.0 & Sagittal & $3 \mu$ & 156 \\
\hline 11 & 13 & 8.0 & Sagittal & $10 \mu$ & 222 \\
\hline 12 & 14 & 10.0 & Sagittal & $10 \mu$ & \\
\hline 13 & $\cdot 15$ & 12.4 & SagittaI & $10 \mu$ & 294 \\
\hline
\end{tabular}

${ }^{1}$ As given in Normentafeln of Keibel for the rabbit (Keibel, '05). 


\section{METHODS}

In the study of early development of the coelom and its subsequent subdivision by the formation of the pericardium, many drawings have been made with the projection apparatus, and for more accurate interpretation of the facts presented by the material a number of models were prepared by the Born method of wax reconstruction. These models were made at a magnification of one hundred diameters, with the aid of the projection apparatus, by superimposing drawings of the sections from the region of investigation. All the models described here are to be found in the Department of Anatomy, University of Michigan.

The illustrations of the various levels of the models were made by superimposing the sections of the model, and not by making a drawing of each section as an individual division.

\section{LITERA TURE REVIEW}

\section{Early coelom formation and development of pericardial coelom}

The facts regarding the division of the germ layers and formation of the embryonic coelom are now generally accepted. Mall ('10), in describing the early coelom development in human embryos, states that the coelomic spaces arise in both sides of the embryo, but are so irregular in position and form that their arrangement is not to be considered as metameric. In his earlier papers Mall considered that all or nearly all of the body coelom was formed by an incorporation of extra-embryonic coelom. The small cavities in the body mesoderm were considered to belong to the muscle plates and early blood vessels, and not to have any part in body coelom development. At that time Mall was convinced that the whole peritoneal cavity was simply pinched off from the coelom of the outside (extra-embryonic coelom) and that the pleural and pericardial cavities were probably formed in the same manner.

This primary description of Mall was based on Graf Spee's description of the young human embryo Gle. Between this embryo and older human embryos a large gap exists which 
is filled by Bonnet's ('89) study of the sheep embryo. In the sheep the pericardial coelom appears as irregular spaces on either side of the head much as in Spee's embryo Gle. These spaces were described as next uniting, forming in a relatively short time large spaces on either side of the body, which soon unite with each other at the extreme anterior end of the embryo, forming a horseshoe-shaped canal in the mesoderm on the ventral side of the head. Throughout the entire devel. opment of the pericardial coelom it was described as being closed on its lateral sides and having no direct communication with the extra-embryonic coelom, except through its later and indirect connection through the peritoneal coelom.

Bonnet ('89) also noted that in the sheep the whole pericardial coelom was formed hand in hand with the invagination of the foregut before the endothelial anlage of the heart had arranged itself into vascular tubes.

The work of Strahl and Carius ('89) on the guinea-pig and rabbit further shows that the pericardial cavity arises very early and independently of the exocoelom. In the rabbit, according to these investigators, the pericardial coelom ends in two dorsal and two ventral recesses, all four of which connect subsequently with the peritoneal coelom.

In the light of the facts presented by comparative embryology, Mall was evidently convinced that his earlier statements regarding early coelom formation were incorrect. In his article in Keibel and Mall's Human Embryology ('10), we find the following statement:

The coelom of the embryo arises independently of the exocoelom in embryos between 1.5 and $2.0 \mathrm{~mm}$. long. In specimens less than 1.5 $\mathrm{mm}$. studied by Peters, Graf Spee, and Minot, there is no trace of either blood vessels or body cavity within the embryo, but in Graf Spee's well-known embryo Gle $(1.54 \mathrm{~mm}$. long) traces of the beginning of the heart and its coelom are present.

\section{Early heart development}

While this work is not directly concerned with heart development, the question of the formation of this structure and its associated vessels has considerable importance in the prob- 
lem at hand, so that a brief résumé of the literature related to heart formation will be given.

The early workers on the origin of the heart were Balfour, Hensen, His, Lockwood, Born, and Kölliker, and recently Yoshinaga ('17) has added a very valuable contribution.

Lockwood ('89) describes the heart in the rabbit as beginning during the eighth day of embryonic development, its commencement being indicated by a slight bending of the splanchnopleure into the widely separated halves of the coelom. The splanchnic cardiac loops are described as growing rapidly during the eighth day and, according to Balfour ('81), each acquires an endothelial lining which is derived from splanchnic mesoblast.

Later steps in heart development are described by Yoshinaga ('17), working in this laboratory, who furnishes a review of important literature relating to the subject which will not be repeated in this paper.

In describing later heart development in the rabbit Lockwood ('88) states that by the beginning of the ninth day the heart is a slightly bent tube attached dorsally to the pharynx by the supracardiac splanchnopleure, which has become the mesocardium posterius (dorsal mesocardium), and to the ventral wall of the coelom by the infracardiac splanchnopleure, which has become the mesocardium anterius (ventral mesocardium). Lockwood describes these mesocardia as being formed when the two halves of the coelom come together as a result of the formation of the head fold and lateral body folds.

While Lockwood ('88) describes the presence of a ventral mesocardium for a time in the rabbit embryo, its presence in the human is strictly denied by Thompson ('08). Strahl and Carius ('89) also admitted the presence of such a structure in the rabbit. Lockwood ('88) describes the two mesocardia in the rabbit, giving as their function the separation of the two halves of the coelom, and only after their breaking down does he admit the presence of a single coelom in the region of the heart. The ventral mesocardium is said by this investigator to be broken down early in the ninth day, with possibly a few remnants persisting for some days. 


\section{Blood vessels and important relations}

Associated with the heart in its early formation and with the early body cavity and its separation are the important blood vessels of the embryo. Lockwood ('88) describes the vitelline (omphalomesenteric) veins as first appearing early in the ninth day and running in from the blastoderm at right angles to the axis of the embryo, to enter the heart. These vessels begin in the vascular area by means of a network and reach the heart by way of the splanchnopleure by passing across the ventral boundary of the coelom. As their passage is at right angles to the axis of the embryo, they form a demarcation between the cardiac and pleuroperitoneal portions of the cavity and are the first factors concerned in separating one part of the coelom from the other. The separation is described by Lockwood (' 88 ) as being effected in the following manner:

The venous end of the heart and the cardiac ends of the omphalomesenteric veins are fixed to the ventral wall of the pharynx by the dorsal mesocardium, and in addition, after the early part of the ninth day, the veins become fastened by an adhesion, the 'mesocardium laterale' (of Kölliker, '79), to the somatopleure, at a point which is almost at the same level as their entry into the heart, but some distance nearer the lateral limits of the embryo. By this formation a portion of the coelom is converted into a passage which has the following boundaries; in front, the cardiac end of the omphalomesenteric vein; behind, the body wall; externally, the mesocardium laterale; internally, the dorsal mesocardium and the pharynx.

This passage described above as being produced between the pericardial and pleuroperitoneal cavities was designated by Lockwood as the 'iter venosum,' because of its being formed by a vein (omphalomesenteric) and being closed by another vein (ductus Cuvieri).

Lockwood uses the term 'mesocardium laterale' as representing a union of somatic and splanchnic structures and being a route by which the somatic veins find ingress into the splanchnic. It may be considered as the place where the cleft mesoblast gives place to that which is uncleft, and its exact 
position in sections is marked by the passage of the somatic into the splanchnic veins.

Various opinions have prevailed as to the identity of the vein which passes through the lateral mesocardium. Kölliker and Uskow ('83) spoke of it as being the anterior cardinal and Balfour spoke of it as being the Cuvierian duct. Lockwood ('88) has shown that neither of these alternatives holds good in the rabbit, because the vein transmitted runs from the tail end forward in the side body wall, and, therefore, corresponds neither to the anterior cardinal nor to the Cuvierian duct, but is the umbilical vein. It is described as being developed after the lateral mesocardium and sooner upon one side of the embryo than upon the other.

\section{Septum transversum}

The common body cavity, as previously described, is first partially divided into subdivisions by a structure known as the 'septum transversum,' first discovered and described by His and designated by Cadiat as the 'mesodermal partition' and by Uskow as the 'massa transversa.' According to His, the body cavity in the early embryo is divided into the 'parietalhöhle' and the communication between the two is termed the 'parietal recess' ('iter venosum' of Lockwood, as previously described). The 'parietalhöhle' from its earliest appearance contains the heart and is destined to form the pericardial cavity. A portion of the parietal recess forms the pleural cavity and the remainder of the recess is added to the general peritoneal cavity.

Since the time of His (1881) several other investigators have added to our knowledge of comparative embryology by valuable contributions. One may mention particularly the work of Ravn on birds and rabbits; Wolfel, on ruminants; Lockwood ('88), Brachet ('95), and Uskow ('83), on rabbits; and Robinson, on rats and mice; while Mall ('91, '10), Broman, and Thompson ('08) have given detailed accounts of the development of the diaphragm in man, and have dealt with the arrangement of the septum transversum in embryos of various stages of development. 
In a description by Brachet ('95) of an eleven-day rabbit embryo, a complete explanation of the relation of the vessels connected with the septum is given. This description applies to an older embryo than the one described by Lockwood in section 3. All vessels described open into the sinus venosus.

1. The two omphalomesenteric veins, paired and symmetrical, immediately before penetrating the septum, anastomose by a large transverse branch which crosses the ventral surface of the digestive tube at the moment where this is continued in the omphalomesenteric vesicle.

2. The umbilical veins are uniformly paired and symmetrical at this stage. They are two voluminous vessels, which, coming from the umbilical vesicle, reach the walls of the body of the embryo and penetrate the septum transversum by the right and left lateral borders.

3. As for the ducts of Cuvier, formed by the union of the anterior and posterior cardinals, they form the proximal and dorsal limit of the septum transversum and, forming an almost transverse course, come to connect with the sinus venosus.

\section{Completion of pericardial cavity division}

It is to Jean Müller that we are indebted for our first knowledge of the development of the peritoneum and the change of position of the organs of the coelomic cavity of man. Toldt published a work on this subject which constitutes the basis for all our present knowledge. Since that time there is the work of Uskow ('83), His, Cadiat, Kölliker, Lockwood ('88'89), Klaatsch, and, more recently, that of Mall ('01, '10), which deals with the problem in man and in many other forms, as has already been pointed out.

In a rabbit embryo of ten days the three coelomic cavities communicate with one another. The pericardial cavity is separated from the remainder of the general cavity solely at its posterior part by the septum transversum, which has been described. The septum transversum forms a dorsal wall for the caudal end of the primitive pericardial cavity and a ventral wall for the primitive pleuroperitoneal cavity. 
One of the next steps in the separation of the cavities is the closure of the 'iter venosum' of Lockwood. The problem of the closure of this passage has been a matter of dispute. In man and the rabbit, His attributed the closure mainly to the approximation of the ducts of Cuvier. Lockwood ('88) arrived at a similar conclusion. Uskow ('83) mentioned three factors in its occlusion: 1) The general alteration in the position of the foremost part of the lateral mesocardium; 2) a thickening of the 'massa longitudinalis' (a name given by Uskow to the tissue along the side of the trachea and oesophagus) ; 3) a cell increase in the 'massa transversa' ('septum transversum' of His).

The next step in the further separation of the cavities is the formation of a membrane between the pericardial and pleural cavities, a membrane known as the 'dorsal pericardium' of Lockwood, and designated as the 'pleuropericardial' membrane by His, Uskow, and Mall. The following description is given by Lockwood ('88) of this structure:

The eleventh day witnesses the commencement of a dorsal perieardium, which is a mesoblastic septum uniting the venous end of the heart and the omphalomesenteric veins to the body wall, and continuous with the dorsal part of the septum transversum. The structure seems to be formed partially, perhaps, from the lateral mesocardium, but mainly by elongation of the septum transversum. From its earliest formation it constitutes a partition betwixt the cardiac portion of the coelom and the foremost part of the pleuroperitoneal cavity, that is, the part in which the lungs lie.

His attributes the formation of the pleuropericardial membrane to the separation of the Cuvierian ducts from the body wall. Brachet ('97) regarded this membrane as being only a secondary extension of the septum transversum. According to Lockwood ('88), by the end of the thirteenth day of development of the rabbit there is no trace of any communication between the pericardial and pleuroperitoneal cavities.

\section{OBSERVATIONS}

The object of this study is to attempt to verify facts given in previous works and to find, if possible, new factors which 
may enter into the problem of early coelom development and later subdivision of the primitive cavity, and to determine explanations for many of the processes which do occur.

In beginning this study it soon became apparent that the problem was intimately connected with that of blood-vessel formation and heart development, so that it is necessary to first give a rather general account of relations in very young embryos to form a background for the later stages which will be presented and in the study of which reconstructions were prepared. In the later stages the description will be confined more to the region under direct investigation.

\section{Embryo no. 1}

The first embryonic shield in the collection in which there was any coelom present was removed from the uterus nine days after insemination, was cut in cross-section $10 \mu$ in thickness, and 199 sections were cut from the embryonic shield. This embryo was slightly further developed than the one described by Lockwood ('88) in which the anlage of the heart first appears. There was no indication of any coelom or heart anlage in a seven-day rabbit and no eight-day rabbit was present in the series examined; but with the stage of development already reached in the nine-day rabbit, the heart anlage and pericardial cavity being present, and the absence of either structure in the seven-day rabbit, is evidence of the beginning of these structures during the eighth day of embryonic development.

In the mesoderm five mesodermal somites are to be observed, beginning with section 73 and continuing through section 103. The somite is rather elongated, with large mesodermal cells circularly arranged in a single layer, indicating that a cavity (mesocoele) is to be formed, but none of the somites of this embryo contained a cavity. The mesoderm is a solid plate except in the region of the future heart, where small spaces are present, the anlagen of the future pericardial cavity. The cephalic extent of this cavity is section 14, which is far anterior to the forward extent of the notochord and 
somites, showing that in early development the pericardial coelom is to be observed far forward in the head region. The mesoderm in the region of the primitive cavity is thickened and the splanchnic layer is much thicker than the somatic layers, as figure 1 will show. No extra-embryonic coelom is to be observed in this embryo, which gives evidence to the fact that the embryonic coelom arises independently of the extraembryonic coelom.

There is no indication of either head or body folds (lateral folds) being present nor a foregut. A few cells can be distinguished between the splanchnic layer of mesoderm and the entoderm in the region of the future pericardial coelom. These cells resemble the surrounding mesodermal cells, and if the view of Wang ('17) (the biphyletic origin of blood cells and vascular endothelium) is accepted, these must be the cells (angioblasts) which give rise to the endothelial tubes, the anlagen of the future heart.

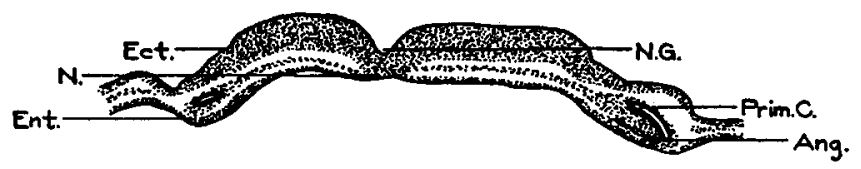

Fig. 1 The thirty-eighth section of a series of 199 sections of a nine-day rabbit embryo (embryo 1) eut in cross-sections of $10 \mu$ thickness. Ang., angioblasts; Ect., ectoderm; N., notochord; N.G., neural groove; Prim.C., primitive coelom. $\times 112$.

Figure 1 is reproduced from the thirty-eighth section, counting from the cephalic extent of the shield. The two mesodermal cavities are evident, the left being better developed in this section than the right. The splanchnic mesoderm is much thicker than the somatic mesoderm. Between the splanchnic mesoderm and the entoderm the few scattered cells (angioblasts), which are the anlage of the heart, are to be observed.

\section{Embryo no. 2}

The second embryo examined was temoved from the uterus nine days after insemination, but is much further advanced 
in development than embryo 1 just described. The embryo was cut in cross-sections of $10 \mu$ thickness, and 270 sections were cut from the embryonic disc. Eleven mesodermal somites can be distinguished. A distinct cavity (mesocoele) is present in each somite, and this is in no section connected with the embryonic coelom which, with the presence of the mesodermal cavity before the mesocoele, as in embryo 1, precludes the possibility of the embryonic coelom in its development having any part of its origin from the primitive cavity of the somite.

The coelom in the mesoderm is well developed in this embryo. The most cephalic extent of this coelom is in section 28. A very marked advance in the development of the circulatory system is to be noted. The dorsal aortae have been formed and the first aortic arch is present in sections 24 to 26 . The ventral aortae can be traced from section 26 caudally to section 36 , where the first section of the endothelial tubes of the heart can be distinguished. These endothelial tubes are at no place fused, and when traced caudally, are seen to be joined by vessels in section 90 which come from the extra-embryonic area and are the omphalomesenteric veins.

Head and body folds are present and the cephalic portion of the body is already formed into a closed structure with a foregut. Ventral to the foregut is the pericardial coelom, which is a U-shaped structure, the dorsal mesocardium being present and serving to suspend the primitive heart and to separate the vertical limbs of the primitive pericardial cavity. No ventral mesocardium is present.

When the endothelial tubes are traced caudad to the region of the anterior intestinal portal (section 66), they may be seen to diverge and to be joined by the omphalomesenteric veins. At this point the single pericardial cavity becomes continuous with two slightly constricted cavities, the 'dorsal parietal recesses' of His ('iter venosum' of Lockwood) which lead to the pleuroperitoneal portions of the embryonic coelom.

Figure 2 is a drawing from section 60 and shows the relations of the pericardial coelom. This figure shows the welldeveloped pericardial coelom as a closed cavity, there being 
no communication with the extra-embryonic coelom in any part of its extent.

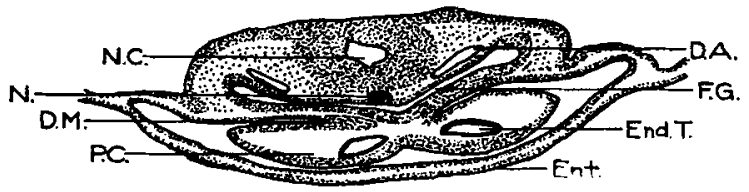

Fig. 2 The sixtieth section of a series of 270 cross-sections of a $10 \mu$ thickness of the embryonic shield of a nine-day rabbit embryo (embryo 2). D.A., dorsal aorta; D.M., dorsal mesocardium; Ect., ectoderm; End.T., endothelial tube; N., notochord; N.C., neural eanal; P.C., pericardial coelom. $\times 112$.

\section{Embryo no. 3}

The third embryo examined was removed from the uterus nine days after insemination and is considerably further advanced in development than the two embryos previously described. There are ten well-developed mesodermal somites in this animal. The lateral-plate mesoderm shows a distinct pericardial coelom, with the heart further developed than in the two previous embryos. The atrioventricular bend is present in the heart. The heart occupies a position slightly more caudad than in the above-described embryos.

At the region of the beginning of the midgut the pericardial coelom becomes continuous with a single cavity and this with two cavities formed by the approximation of the somatic and splanchnic mesoderm, the dorsal and ventral parietal recesses (fig. 3). Only the dorsal recess becomes continuous with the pleuroperitoneal cavity caudally. Strahl and Carius ('89) stated that the pericardial coelom in the rabbit ended in four parietal recesses, two dorsal and two ventral, and that all four subsequently connect with the peritoneal recess. In the embryo under consideration the ventral recesses do not connect with the peritoneal recess, agreeing with Mall's description of the human.

In this embryo other blood vessels are found to be present. Both the anterior and posterior cardinal veins are present and the umbilical veins are forming. The cardinal veins are observed connecting with the omphalomesenterics, forming 
the beginning of the sinus venosus. These veins are more clearly demonstrated in embryo 4, which will not be described here, as it was studied to supplement no. 3, the two apparently being in the same stage of development.

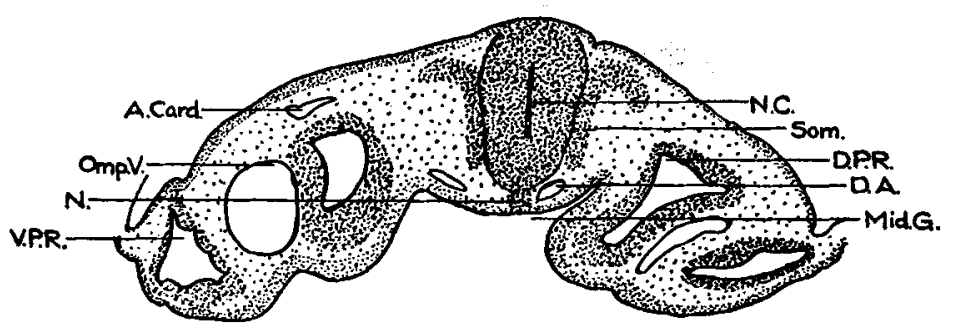

Fig. 3 The $116 \mathrm{th}$ section of a series of 224 cross-sections having a $10 \mu$ thickness of an embryonic shield of a rabbit removed nine days after insemination. A.Card., anterior cardinal vein; D.A., dorsal aorta; D.P.R., dorsal parietal recess; Mid.G., midgut; N., notochord ; N.C., neural canal; Omp.V., omphalomesenteric vein; Som., somite; V.P.R., ventral parietal recess. $\times 112$.

Figure 3 is from section 116 through the region of the anterior extent of the midgut.

\section{Embryo no. 5}

This embryo was removed from the uterus nine days after insemination, and ninety-nine sections of a $10 \mu$ thickness were made from the embryonic shield. This embryo seemed especially valuable in showing early pericardial relations.

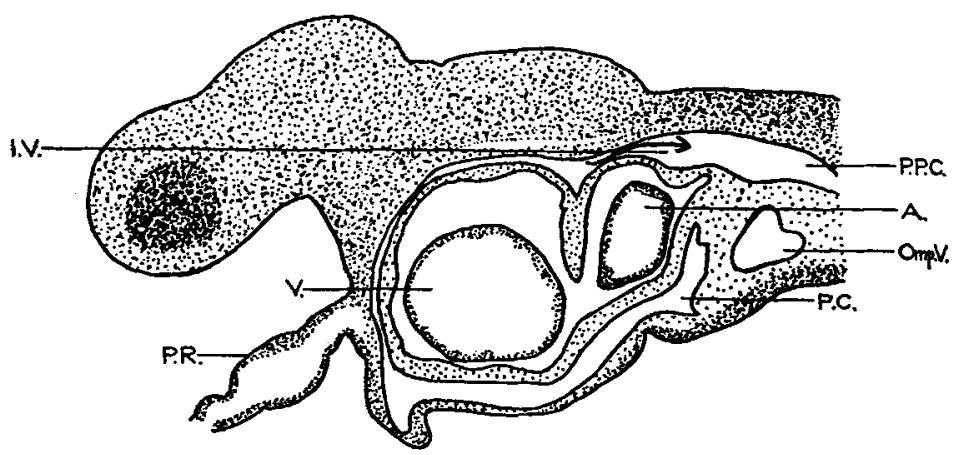

Fig. 4 The thirty-fourth section of a sagittal series of an embryonic shield removed from the uterus nine days after insemination. This level is far laterad of the midline through the iter venosum. A., auricle; I.V., iter venosum; Omp.V., omphalomesenterie vein; P.C., pericardial coelom; P.P.C., pleuropericardial coelom; Pr., proamnion; $V$, ventricle. $\times 112$. 
Figure 4 is a diagram of section 34 and is far laterad of the midaxis of the body. This diagram illustrates the connec-. tion of the pleuroperitoneal cavity with the iter venosum. A study of the relations of the iter in this figure and in figure 3 will reveal the boundaries of this communication between the primitive cavities. These boundaries are the following: dorsally, the body wall; ventrally, the omphalomesenteric vein; externally, the lateral mesocardium; internally, the splanchnopleure, where that membrane is closing behind the venous end of the heart to form the foregut and dorsal mesocardium (Lockwood, '88).

The omphalomesenteric veins are shown here in their course to the heart, running at right angles to the longitudinal axis of the embryo and having their course in the splanchnopleure. As they approach the heart, as this diagram shows, they assist in forming a demarcation between the pericardial and pleuroperitoneal cavities, the beginning of the structure known as the septum transversum, through the substance of which the omphalomesenteric veins run in later development.

\section{Embryo no. 6}

The next embryo under consideration was removed from the uterus nine days after insemination and is slightly further advanced in development than embryo 5 .

This figure shows the increased forward extent of the foregut and the relatively more caudal position of the pericardial coelom, this being due almost entirely to the presence in this embryo of the cranial flexure. In addition to the more caudal position of the pericardial coelom is the increase in its diameter in a dorsoventral direction. The heart is also observed to have increased in size. The splanchnopleure still forms the ventral wall of the pericardial cavity as in the previous embryos. The first aortic arch has been formed and is illustrated in this figure as it arches around the cephalic portion of the foregut.

In a further study of this embryo the omphalomesenteric veins may be traced laterally to the yolk sac, where they have 


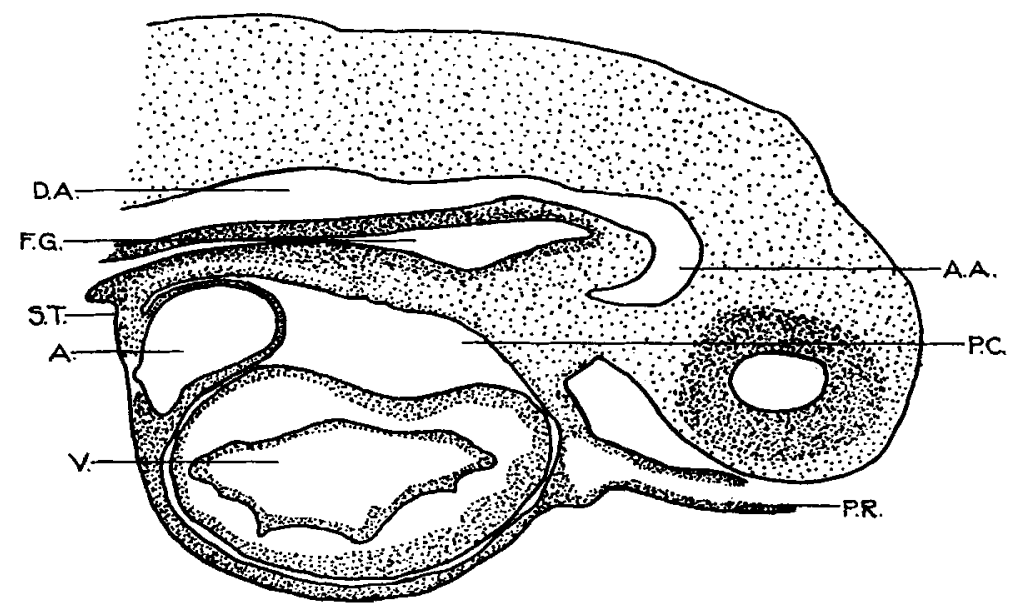

Fig. 5 The twenty-sixth section of a series of eighty-one sagittal sections having a $10 \mu$ thickness. This embryonic shield was removed from the uterus of a rabbit nine days after insemination. A.A., aortic areh; $A$., auricle; F.G., foregut; D.A., dorsal aorta; P.C., pericardial coelom; Pr., proamnion; S.T., septum transversum; $V$., ventricle. $\times 112$.

their origin. In this series the septum transversum is more evident than in the former embryos. Since the omphalomesenteric vessels are attached laterally (at their origin) and in their course to the body wall, the sinus venosus, which is formed partly by their union, cannot alter its position and the bulging of the splanchnopleure which is produced by these vessels forms the well-marked septum transversum. Due to the fixation of the vessels, a caudal retroflexion (Lockwood, '88) of the splanchnopleure may be noted which also assists in the formation of the septum. This retroflexion is illustrated in figure 5. In this embryo the septum transversum is opposite the third mesodermal somite.

\section{Embryo no. 7}

The embryo under discussion was removed from the uterus ten days after insemination and cut in cross-sections $3 \mu$ in thickness. A great increase in the size of the heart and pericardial cavity is to be noted. The heart is still far forward in the head region, the otic vesicle, which is open, being lo- 
cated opposite the middle of the pericardial region (fig. 10). The heart is an S-shaped structure consisting of sinus venosus, auricle, ventricle, and truncus arteriosus, which gives origin to the two ventral aortae. The first and second pairs of aortic arches are present.

Both the anterior and posterior cardinal veins are developed as well as the umbilical and omphalomesenteric vessels, so that the entire primitive system of blood vessels was formed during the ninth and early part of the tenth days of development, the order of appearance of these vessels being summarized as follows: omphalomesenterics first, followed by the umbilicals; then the anterior cardinals, and finally, the posterior cardinals.

A study of this series revealed what was first thought to be a portion of ventral mesocardium present in a few sections which fall immediately anterior to the septum transversum. Since there has been much discussion and disagreement among investigators regarding the presence or absence of such a structure in mammals, a reconstruction of the entire pericardial region of this series was prepared to demonstrate whether a true ventral mesocardium was present or whether the structure observed was a portion of the septum transversum obliquely cut, as explained by Wang ('17). The structure begins, when tracing the series caxdally, as a small tip from the ventral surface of the heart, gradually increases in length through a distance of twelve sections $(36 \mu)$, and finally, as revealed by the reconstruction, joins with and is definitely a part of the septum transversum. Figure 6 is a diagram from a section in the anterior portion of the septum transversum, showing the structure which has probably been considered by many investigators to be ventral mesocardium. This figure also shows on the left side the pericardial coelom, while on the right side the coelom is divided into two parietal recesses, dorsal and ventral. The ventral parietal recess ends blindly as the septum transversum is approached, while the dorsal recess serves as the canal of communication between the pericardial coelom and the caudal portion of the primitive coelom. 


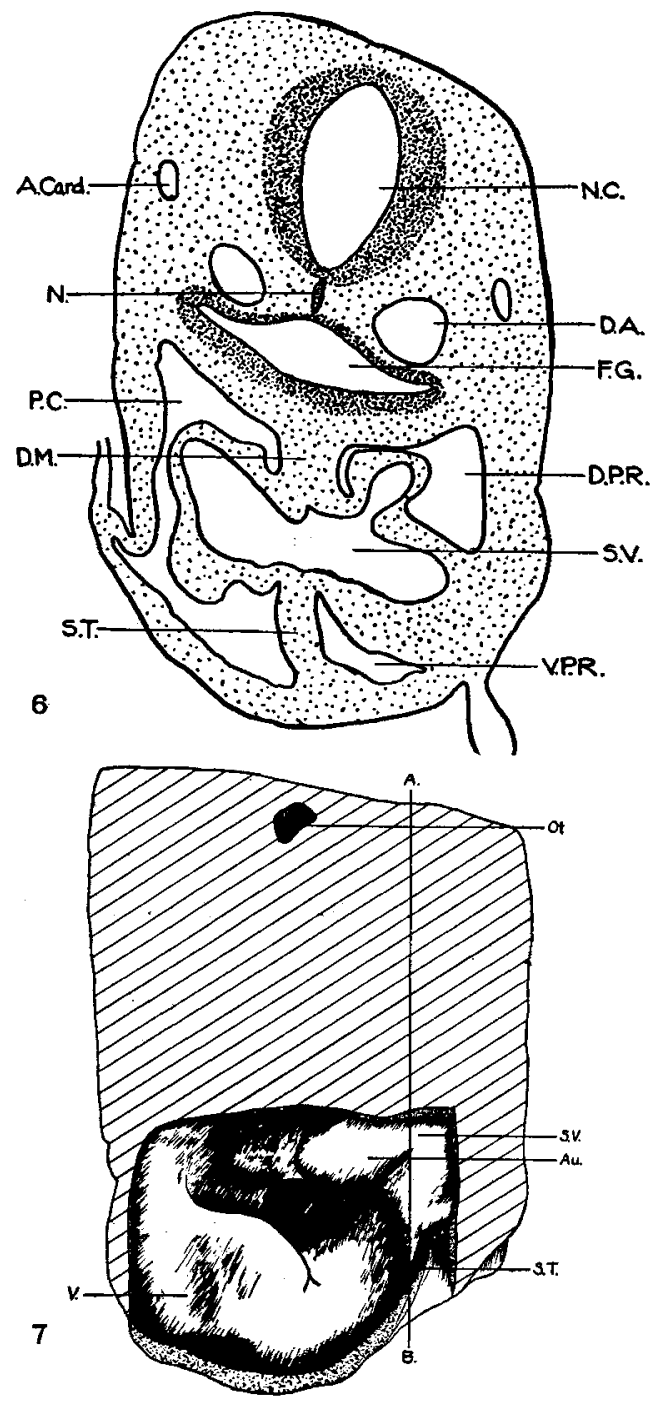

Fig. 6 This figure is drawn from a cross-section of a nine-day embryo which was eut in $3 \mu$ sections. The plane of section illustrated in this figure is shown in figure 7 , line $A-B$. The structure labeled S.T. was originally thought to be ventral mesocardium, but the reconstruction demonstrated it to be an anterior extension of the septum transversum. A.Card., anterior eardinal vein; D.A., dorsal aorta; D.M., dorsal mesocardium; D.P.R., dorsal parietal recess; F.G., foregut; L.M., lateral mesocardinm; N., notochord; N.C., neural canal; S.T., septum transversum; V.P.R., ventral parietal recess. $\times 112$.

Fig. 7 Lateral view of a reconstruction of the pericardial region of a ten-day embryo (embryo 7). Lateral wall of pericardial coelom has been removed. Line $A-B$ indicates plane of section drawn in figure 6 . Ot., otocyst; $A$., auricle; $V$. ventricle; S.T., septum transversum. $\times 50$. 
Figure 7 is a diagram of the lateral surface of the reconstruction of this embryo. The wall of the left side of the pericardial cavity was removed to expose the heart and septum transversum. The small ventral tip, which was thought to be ventral mesocardium, is clearly illustrated as being a portion of the septum transversum, so that no ventral mesocardium is present. As illustrated in figure 6, the heart is suspended from the ventral surface of the foregut by the dorsal mesocardium, which is continuous with the parietal pericardium lining the pericardial coelom and with the visceral pericardium which directly enclosed the heart.

\section{Embryo no. 8}

This embryo was removed from the uterus ten days after insemination and was cut in sagittal sections $5 \mu$ in thickness. A reconstruction of the pericardial region and the immediately related portions was made and the description given here is based largely on the model.

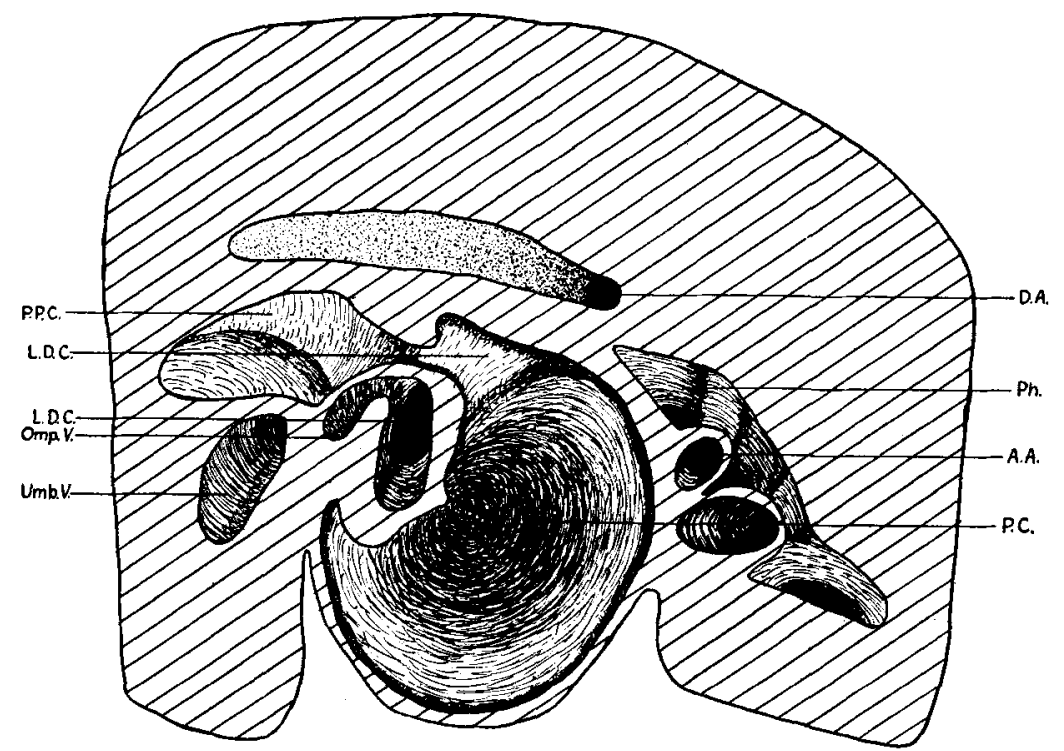

Fig. 8 Medial view of left portion of the pericardial region of a ten-day rabbit embryo (embryo 8), the section being through the left pleuropericardial canal. $A . A$., aortic areh; D.A., dorsal aorta; L., lung anlage; L.D.C., left duct of Cuvier; Omp.V., omphalomesenteric vein ; Ph., pharynx; P.C., pericardial coelom; P.Pl.C., pleuropericardial canal; $U m b . V$., umbilical vein. $\times 40$. 
The body coelom forms a free space which anteriorly encircles the heart, and in this region is present as a single (unpaired) cavity. The coelom continues on each side of the body over the omphalomesenteric veins to the root of the umbilical vesicle. This caudal continuation of the coelom has developed within it on each side the early anlagen of the lung, which are present as small masses of mesenchymatous cells, and the anlagen of the liver and stomach. The open communication between the anterior pericardial portion of the coelom and the pleuroperitoneal portions of the cavity is present on either side for a thickness of nineteen sections $(95 \mu)$. This is the communication designated by Lockwood as the 'iter venosum,' or more significantly known as the pleuropericardial canal. These communications will be pointed out in the figures of this embryo.

Figure 8 is reproduced from a level of the model through the left pleuropericardial canal. The left dorsal aorta is shown as it passes caudad, the portion illustrated being anterior to the point of fusion of the two anterior divisions. The aortic arches, which join the dorsal aorta laterad to this level, are illustrated with the pharyngeal pouches. The left omphalomesenteric and umbilical veins are present and pass as separate structures to enter, with the left duct of Cuvier, the sinus venosus. The pleuropericardial canal shows a constriction in its lateral surface which is produced by the left duct of Cuvier which projects into the canal in its course to the heart. The course of this vessel is illustrated by the broken line, and is noted to follow in a slightly ventrocaudal direction and then to turn medially to join the sinus venosus. This lateral constriction of the pleuropericardial canal produced by the duct of Cuvier marks the beginning of the closure of that communication.

Figure 9 is through the level of the right pleuropericardial canal, which is constricted in its lateral side by the right duct of Cuvier in its course to the sinus venosus. A comparison of the course and relations of the two ducts of Cuvier shows them to have the same relations on either side, the left duct being slightly longer than the right. 


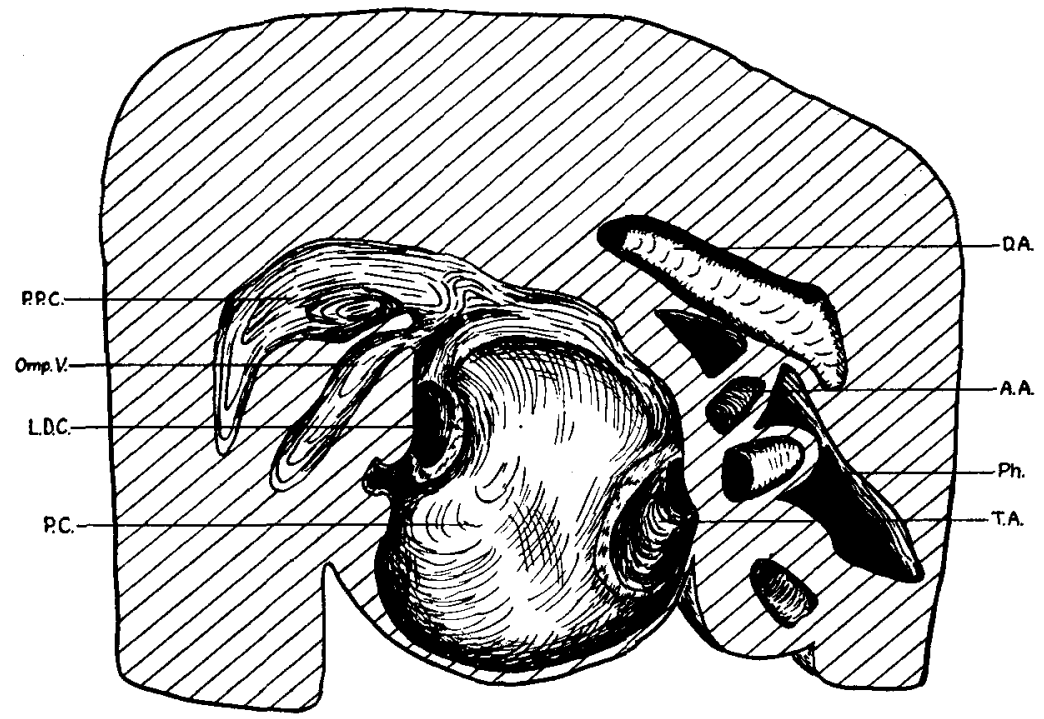

Fig. 9 Lateral view of reconstruction of pericardial region of embryo 8 through level of right pleuropericardial canal. A.A., aortic arch; D.A., dorsal aorta ; L., lung anlage; L.D.C., left duct of Cuvier; Omp.V., omphalomesenteric vein; Ph., pharynx; P.C., pericardial coelom; P.Pl.C., pleuropericardial canal; T.A., truneus arteriosus. $\times 40$.

\section{Embryo no. 9}

The embryo under consideration was removed from the uterus eleven days after insemination and was cut in sagittal sections $3 \mu$ in thickness.

Figure 10 is a diagram reproduced from the model through the level of the left duct of Cuvier. This shows the union of the anterior and posterior cardinal veins to form the duct of Cuvier and its ventrocaudal direction in its course to the heart. This illustration shows the duct of Cuvier forming part of the dorsocaudal boundary of the pericardial coelom. A further study of the reconstruction reveals the left duct of Cuvier passing medially almost as far as the midline of the body before it joins the sinus venosus, and in the latter half of its course it projects free into the pericardial coelom. This vessel forms a prominent lateral constriction in the left pleuropericardial canal. The long course of the left duct of 


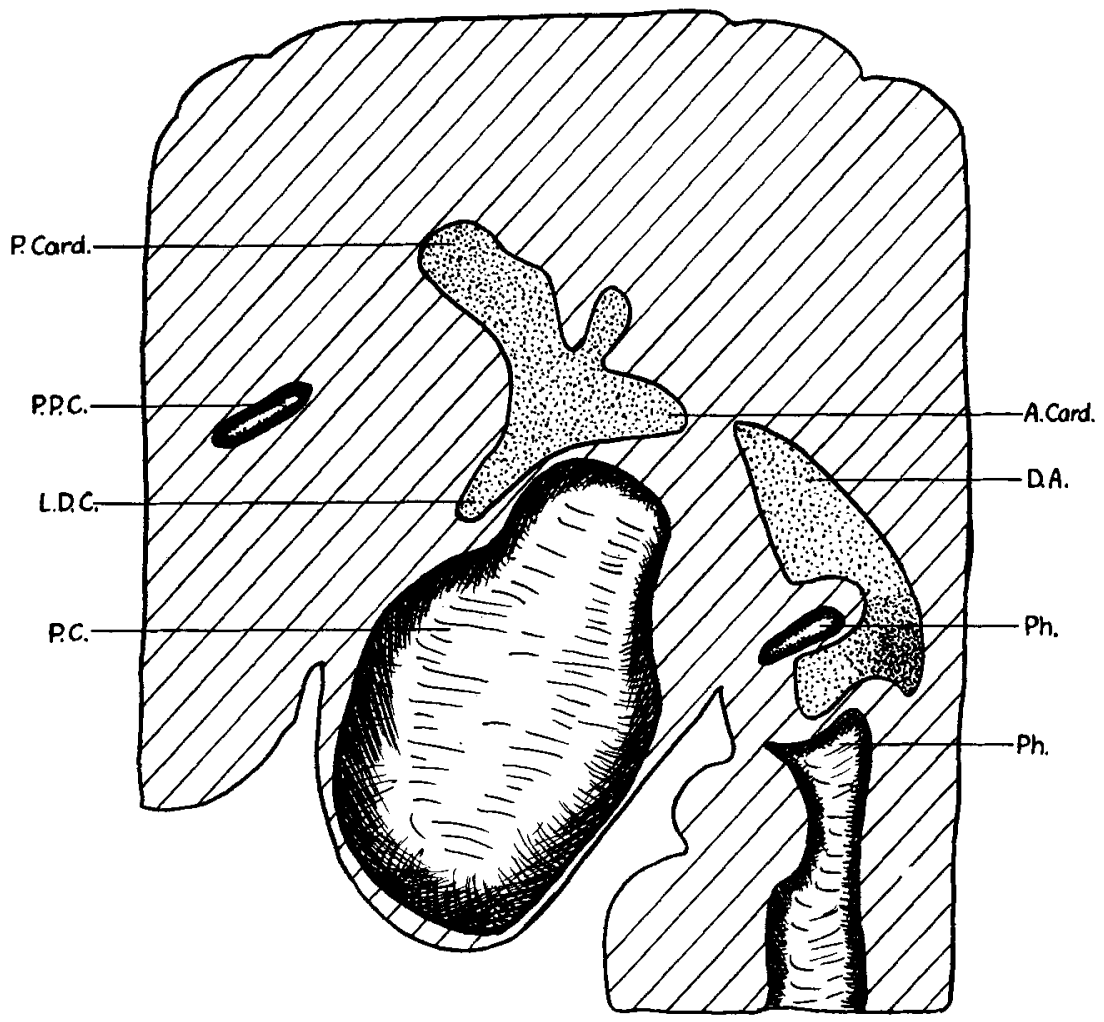

Fig. 10 Medial view of reconstruction of left portion of pericardial coelom of an eleven-day embryo (embryo 9). The formation of the duct of Cuvier is illustrated at this level. A.Card., anterior eardinal vein; A.A., aortic arch; D.A., dorsal aorta; L., lung anlage; L.D.C., left duct of Cuvier; Ph., pharynx; P.C., pericardial coelom; P.Pl.C., pleuropericardial canal. $\times 40$.

Cuvier indicates the beginning of the sinus venosus to assume the relation and position which it will ultimately have in the heart structure, and as it alters its position in becoming a portion of the right side of the heart, it carries the vessels which enter it from the left to the right, thereby producing the relatively longer left duct of Cuvier.

Figure 11 is through the level of the right pleuropericardial canal. In the canal is the lung anlage, which consists of a mass of mesenchymatous tissue surrounding a small, primitive lung bud. The tracheal groove is open and can be observed to con- 


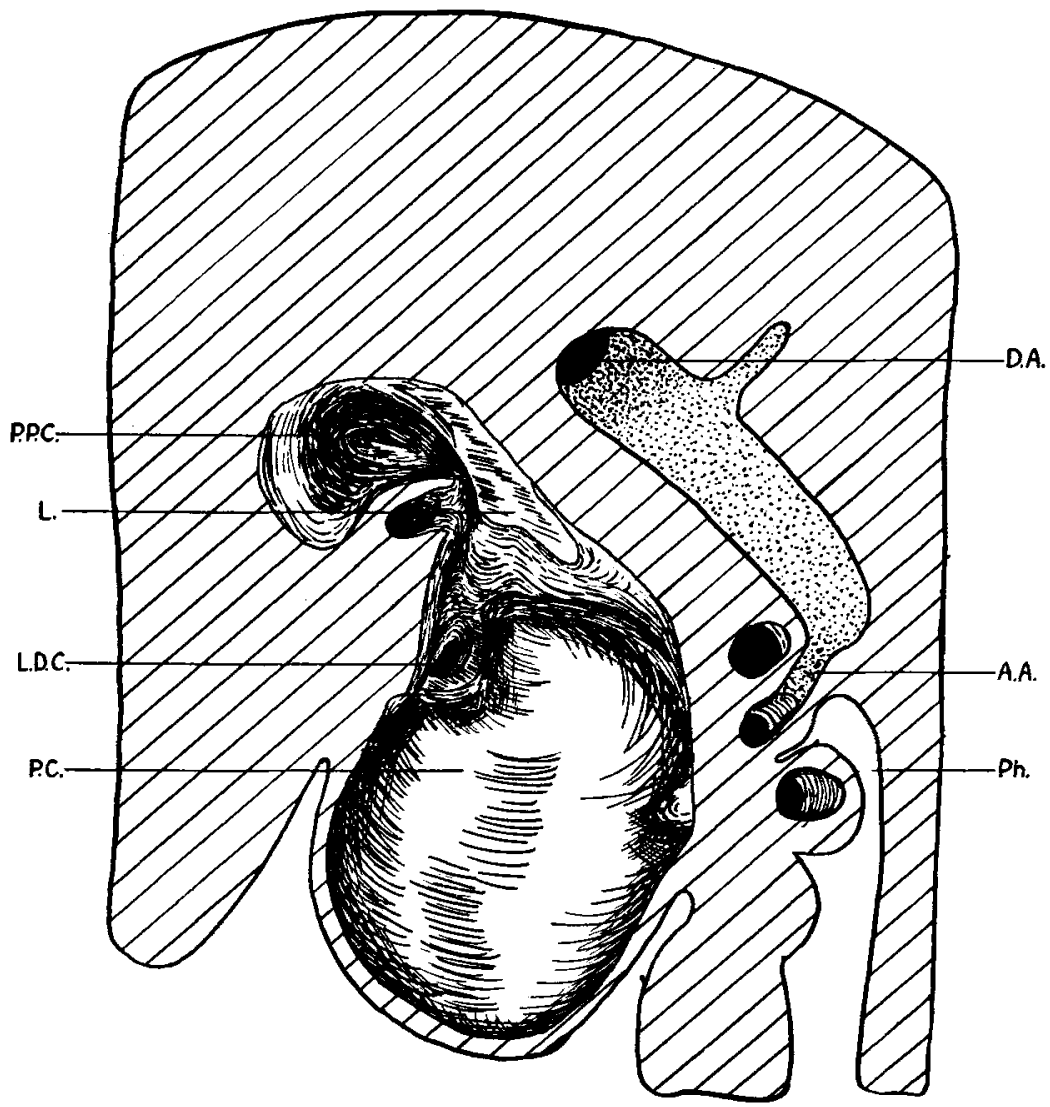

Fig. 11 Lateral view of reconstruction of pericardial region of embryo 9 through the level of the right pleuropericardial canal. A.A., aortic areh; D.A., dorsal aorta; L., lung anlage; L.D.C., left duct of Cuvier; Ph., pharynx; P.C., pericardial coelom; P.Pl.C., pleuropericardial eanal. $\times 40$.

nect with the ventral wall of the pharynx in the midline. The left duct of Cuvier is here illustrated, the level shown being that at which it joins the sinus venosus. The right omphalomesenteric vein is shown at the level at which it joins the heart. A small portion of the truncus arteriosus is illustrated projecting into the pericardial coelom, and medial to the level shown here it gives origin to the aortic arches. The fourth arch is joining the dorsal aorta at this level. 


\section{Embryo no. 10}

This embryo was removed from the uterus twelve days after insemination and was cut in sections $3 \mu$ in thickness. A reconstruction was made of the pericardial region of the embryo, and the important relations are not unlike those of the eleven-day embryo.

The right duct of Cuvier passes immediately laterad of the right pleuropericardial canal and follows a ventral and slightly caudal course to join the right side of the sinus venosus. The ducts of Cuvier on either side form part of the posterior and dorsal wall of the pericardial coelom and do not project free into that cavity. The left duct of Cuvier is much longer than the right, passing ventrocaudally and then medially to join the sinus venosus.

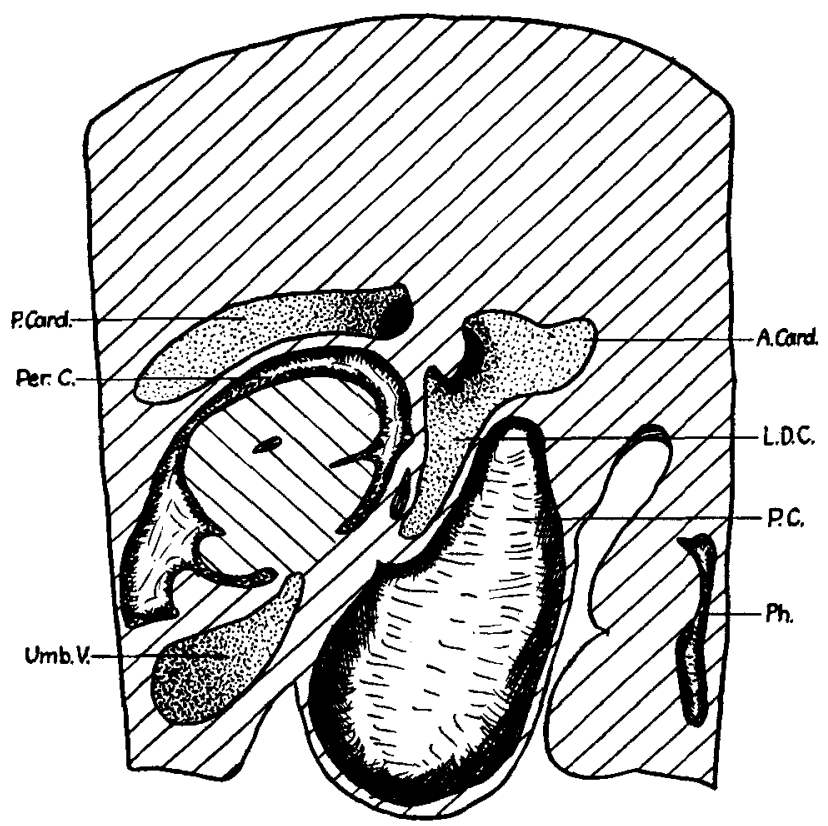

Fig. 12 Medial view of left portion of pericardial coelom from a reconstruction of a twelve-day embryo (embryo 10). This level shows the left duet of Cuvier projecting into the pericardial coelom and attached caudally to the septum transversum. A.Card., anterior cardinal vein; L.D.C., left duct of Cuvier; P.C., pericardial coelom; P.Card., posterior cardinal vein; Per.C., peritoneal cavity; S.T., septum transversum; Umb.V., umbilical vein. $\times 25$. 
Figure 12 shows the formation of the left duct of Cuvier and shows it projecting into the pericardial coelom, and at this level the pericardial coelom is completely separated from the pleuroperitoneal eavity. The duct of Cuvier is seen to have between it and the dorsal extension of the septum transversum a continuation of the pericardial coelom, marking the beginning of the separation of the duct of Cuvier from the septum transversum. The membrane at the caudal boundary of the pericardial coelom at the point where the duct of Cuvier is beginning to project free into the coelom is known as the 'dorsal pericardium' of Lockwood or the 'pleuropericardial membrane' of His, Uskow, and Mall. Due to the position of its origin, it may come in part from the lateral mesocardium at its lateral limit, but as the membrane becomes more extensive and is formed farther medially as the pleuropericardial canal is gradually occluded in its lateral side, it appears to be more directly a dorsal continuation of the septum transversum.

\section{Embryo no. 11}

This embryo was removed from the uterus thirteen days after insemination and was cut in sagittal series $10 \mu$ in thickness. A plastic reconstruction of the pericardial region and its important related structures was prepared.

The ducts of Cuvier are formed on either side by large anterior cardinal veins and by much smaller and very short posterior cardinal veins. This indicates that much of the blood carried by the posterior cardinal veins is now being returned to the heart by the posterior vena cava, which is present for the first time in the thirteen-day embryo. The right common cardinal vein is very short, passing caudally and ventromedially to join the sinus venosus, the length of the passage being through a distance of thirty sections $(300 \mu)$, and the opening of this vessel is in common with that of the posterior vena cava as it enters the sinus venosus.

Figure 13 is an illustration of the level of the right duct of Cuvier and shows this vessel projecting free into the pericardial coelom, having become entirely separated from the 


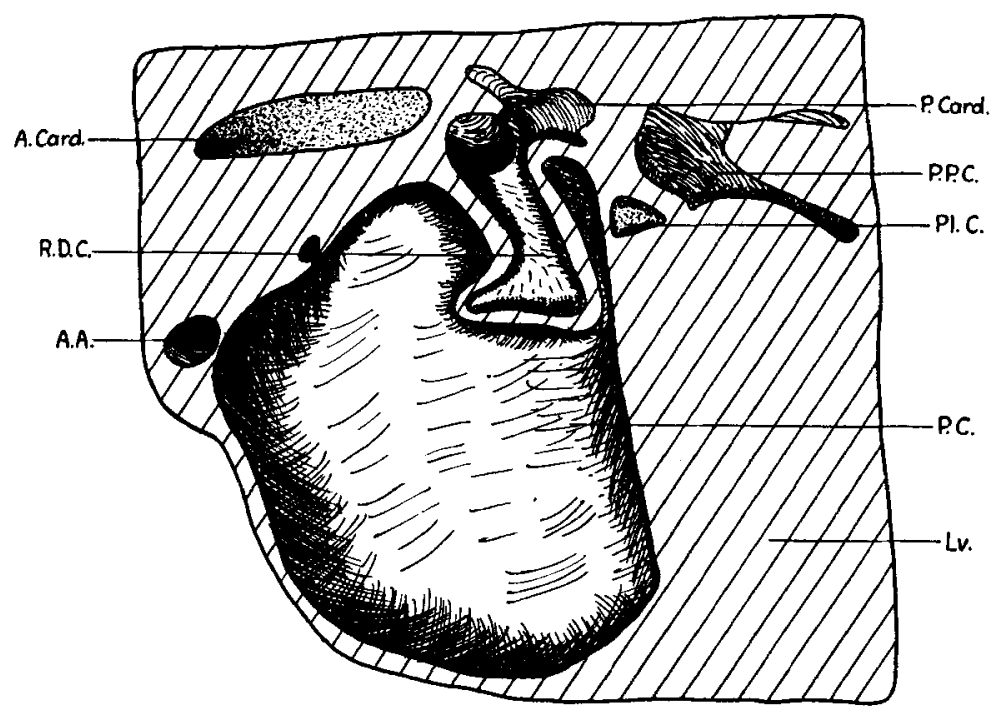

Fig. 13 Medial view of right portion of pericardial coelom from reconstruetion of rabbit embryo removed from uterus thirteen days after insemination. The right duet of Cuvier is to be observed projecting free into the pericardial coelom. A.A., aortic arch; A.Card., anterior cardinal vein; Mes., mesonephros; P.A., pulmonary artery; P.C., pericardial coelom; P.Card., posterior cardinal vein; Pl.C., pleural coelom; R.D.C., right duct of Cuvier. $\times 25$.

septum transversum. The lateral portion of the pleural cavity is illustrated in this figure. A study of the two ducts of Cuvier show these vessels to be coming closer to each other and this approximation has been partly responsible for the closure of the pleuroperitoneal canal.

Figure 14 is through the left pleuroperitoneal canal, which is a very small communication in this embryo. This level is twelve sections mediad to the opening of the left duct of Cuvier into the sinus venosus. This figure shows a small pleuropericardial canal, which is contrary to the observations of Lockwood ('88), who stated that the iter venosum is largest at the end of the ninth day and during the tenth day, and is closed by the commencement of the thirteenth day. This communication is very narrow, being present only through a thickness of six sections $(60 \mu)$. In this figure may also be seen the fourth and sixth arches, with the sixth arch giving 
origin to the pulmonary artery. Laterad to this level the pleural and pericardial cavities are completely separated by the pleuropericardial membrane, which has been formed as the left duct of Cuvier has become separated from the septum transversum, the membrane developing in a medial direction and closing the pleuropericardial canal from the lateral to the medial side. Figure 15 is through the level of the lateral por-

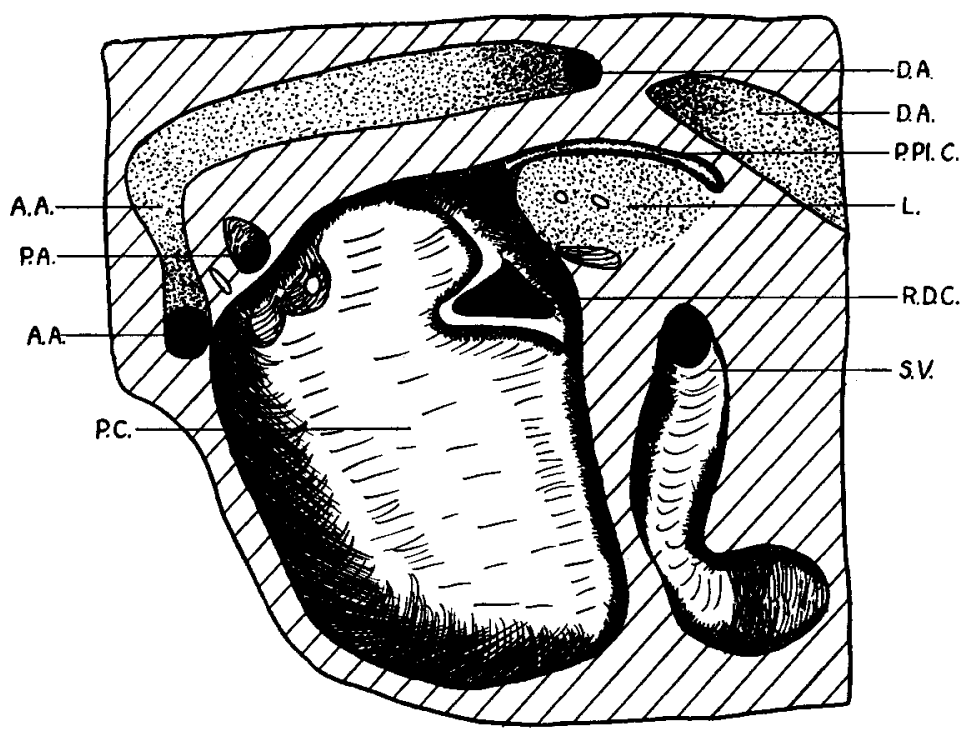

Fig. 14 A lateral view of the pericardial coelom through the level of the left pleuropericardial canal of the reconstruction of the thirteen-day embryo. $A . A$., aortic arch; D.A., dorsal aorta; $D . V$., ductus venosus; $L$., lung anlage; $L v$., liver; P.A., pulmonary arch; P.C., pericardial coelom; P.Pl.C., pleuropericardial canal; R.D.C., right duct of Cuvier; S.V., sinus venosus. $\times 25$.

tion of the left duct of Cuvier and clearly illustrates this vessel projecting free into the pericardial coelom. Lockwood ('88) attributes the closure of the pericardial canal in part to the growth of the mesoblast around the oesophagus and trachea, the mass of cells designated by Uskow ('83) as the 'massa longitudinalis.' The series of models prepared for this present study give no indication of such an influence, the only factor which could be noted as having any importance in 
this closure being the separation of the cardinal veins from the body wall, as first pointed out by His ('81), and the later approximation of these vessels as they become separated from the body wall.

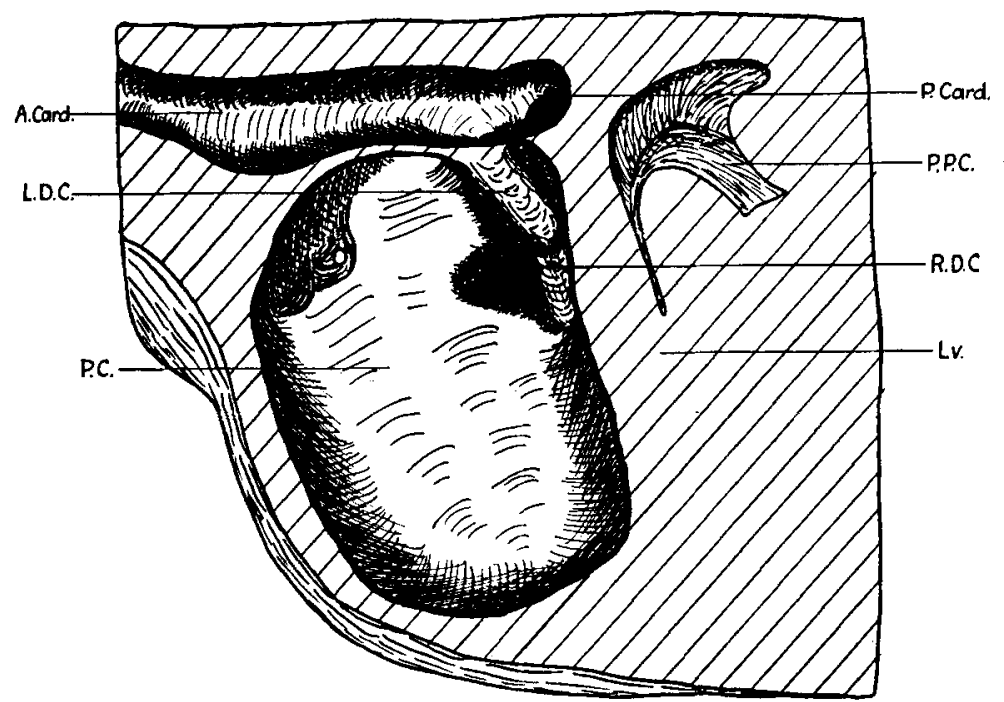

Fig. 15 A diagram through the lateral extent of the left duct of Cuvier of the reconstruction of the thirteen-day rabbit embryo. The pericardial coelom may be observed in part between the left duet of Cuvier and the septum transversum. A.Card., anterior cardinal vein; L.D.C., left duct of Cuvier; Mes., mesonephros; P.C., pericardial coelom; Per.C., peritoneal coelom; R.D.C., right duct of Cuvier. $\times 25$.

\section{Embryo no. 13}

Embryos 12 and 13, while having a difference of one day in their ages, have few differences in their developmental relations, so the description of the last stage in this observation will be confined to the latter embryo. This embryo was removed from the uterus fifteen days after insemination and was cut in sagittal series of $10 \mu$ thickness. A reconstruction of the pericardial region and its associated structures was prepared.

The pericardial cavity is completely separated from the pleural cavity on both the right and left sides of the body. This separation is complete first in the fourteen-day embryo, and 
not in the thirteen-day embryo, as stated by Lockwood ('88) and pointed out in the description of that embryo given above.

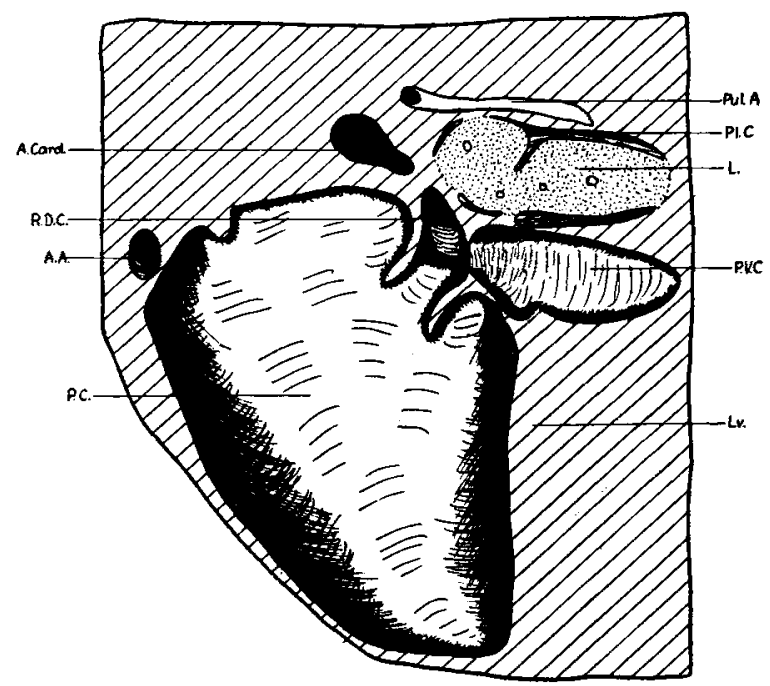

Fig. 16 Medial view of the reconstruction of a fifteen-day embryo (embryo 13) through the level of the right duet of Cuvier. This is the first illustration showing the pericardial cavity completely separated from the pleural cavity. $A . A$., aortie areh; A.Card., anterior cardinal vein; $L$., lung; $L v$., liver; P.C., perieardial coelom; P.P.M., pleuropericardial membrane; P.V.C., posterior vena cava; Pl.C., pleural eavity; R.D.C., right duct of Cuvier. $\times 33$.

Figure 16 is through the level of the right pleural cavity and shows this separation to be complete, the division being due to the pleuropericardial membrane which extends dorsally from the septum transversum to the dorsal body wall, and which has been formed slowly as the duct of Cuvier became farther removed from the body wall and came to project into the pericardial coelom. This latter point is better illustrated in figure 17. Figure 16 shows the opening of the posterior vena cava and right duct of Cuvier at the same level.

Figure 17, through the level of the left pleural cavity and left duct of Cuvier, very clearly shows the pleuropericardial membrane. In the early stages of coelom development, while the septum transversum is opposite the fourth cervical somite, it is said to receive its nerve supply through the phrenic nerve, 
which at that stage must pass through the body wall to reach the septum transversum, but as the ducts of Cuvier leave the body wall and approximate each other, the pleuropericardial membrane is formed and the phrenic nerve then passes through that structure to reach the septum transversum, and the left phrenic nerve is shown in its course through the membrane in this figure.

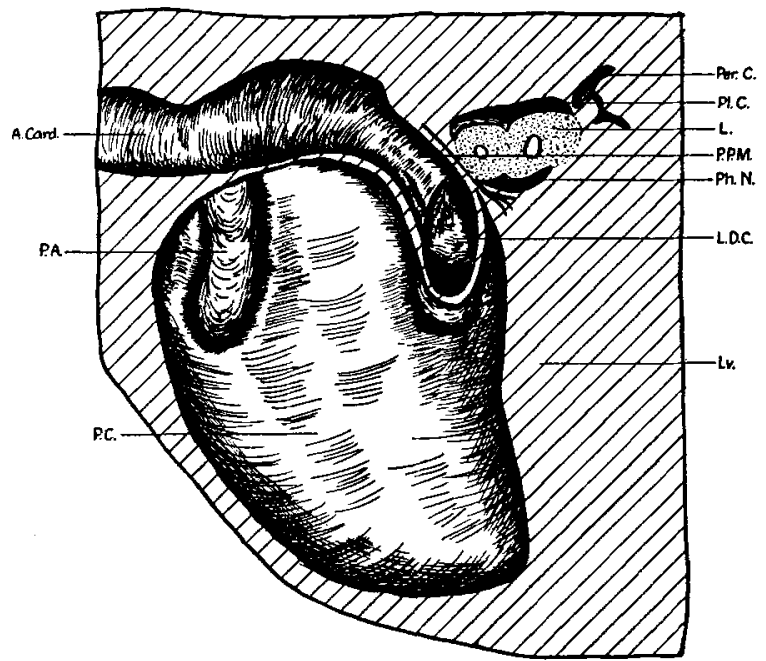

Fig. 17 An illustration from the same reconstruction as figure 16 through the level of the left duct of Cuvier. The phrenic nerve may be observed passing through the pleuropericardial membrane which completes the elosure of the pericardial eavity in this embryo. A.Card., anterior cardinal vein; L., lung; L.D.C., left duet of Cuvier; P.A., pulmonary arch; P.C., pericardial coelom; P.P.M., pleuropericardial membrane; Pl.C., pleural eavity; Ph.N., phrenic nerve. $\times 33$.

The level illustrated in this figure is very near the lateral limit of the left duct of Cuvier, that is, near its origin, but is far mediad to the lateral limit of the pericardial coelom formed by the body wall, which, by comparison with previous embryos, clearly illustrates that as the embryo increases in age the Cuvierian ducts more closely approximate one another and are gradually separated from the body wall. 
SUMMARY AND CONCLUSIONS

In this present investigation, the problem of coelom development and division has been approached in a different manner from that employed by previous workers on the problem. In order to present relations which have not formerly been clearly demonstrated, the reconstructions have been prepared from material cut in the sagittal plane, showing different concepts, especially regarding the formation and relations of the membrane which separates the pericardial and pleural cavities.

The early origin of the coelomic spaces has been generally understood for many years, but there has not been complete agreement as to whether they arise previous to, and independently of, or secondarily to the extra-embryonic coelom and the cavities of the somites. The first part of this work was to confirm earlier observations on this problem. For this purpose seven- and nine-day rabbit embryos were studied, but since no coelomic spaces were evident in the seven-day embryo, a description of that stage has been omitted. The nine-day embryo, embryo 1, shows clearly defined spaces in the lateral-plate mesoderm (fig. 1) and the anlagen for the heart, thus confirming the earlier observations of Lockwood ('88) that the coelomic spaces and the early heart anlagen first appear in the rabbit during the eighth day of embryonic development. These primitive coelomic spaces in the lateralplate mesoderm arise on each side of the body and are not metameric in their origin (Mall, '10).

This present investigation confirms the later statements of Mall ('10) regarding the early formation of the coelomic spaces. In embryo 1 there are spaces present in the anterior region of the embryo (fig. 1), and in this embryo there are also present five mesodermal somites, none of which show any indication of the presence of a cavity, so that we must conclude that these coelomic spaces arise independently of the cavities of the somites. A study of these spaces further shows them to be closed laterally throughout their entire extent, which proves the impossibility of their origin from extraembryonic coelom; in fact, as figure 1 shows, the extra- 
embryonic mesoderm has not yet been split into splanchnic and somatic layers, so that no extra-embryonic coelom is pres. ent. This conclusion is further strengthened by a consideration of embryo 2 and figure 2, which shows the pericardial coelom as a closed cavity except caudally where it communicates with the pleuroperitoneal coelom, and it is only through the latter cavity that it shows any communication with the extra-embryonic coelom. This observation is opposed to Mall's early interpretation of the origin of embryonic coelom from extra-embryonic coelom and confirms his later statements that the embryonic coelom arises independently of the extra-embryonic coelom.

The primitive coelomic spaces in the lateral-plate mesoderm unite to form a continuous cavity which is composed of two horizontal limbs which secondarily unite in the anterior region. The division of the original primitive cavity into subdivisions (pericardial and pleuroperitoneal divisions) is effected by the formation of a transverse partition, the septum transversum, which is formed when the omphalomesenteric veins in their course from the yolk sac to the heart produce a transverse fold in the splanchnopleure as they pass ventral to the coelom (fig. 4). The portion of the coelom anterior to the transverse partition is known as the pericardial coelom, while that caudad is the pleuroperitoneal coelom.

The pericardial coelom consists originally of two horizontal limbs which project far forward into the head (fig. 4). Jater these two horizontal limbs unite anteriorly to form a U-shaped cavity containing the heart. With the later formation of the head bend, the horizontal pericardial cavity is bent ventrad and enlarged, so it then lies in a dorsoventral direction (fig. 5).

With the formation of the septum transversum, which subdivides the primitive coelom, the pericardial portion of the coelom communicates caudally with the pleuroperitoneal portion by two constricted canals, the 'iter venosum' of Luckwood or the 'pleuroperitoneal recesses.' The pericardial cavity ends caudally in four of these recesses, the two dorsal 
and two ventral pleuroperitoneal recesses (fig. 6). All four of these recesses were said by Strahl and Carius ('89) to connect caudally with the pleuroperitoneal coelom, but a study of embryo 7 (ten-day embryo) shows the ventral recesses to end blindly at the septum transversum and only the dorsal recesses continue into the pleuroperitoneal coelom.

A study of the reconstructions produced in this investigation reveals the primitive pericardial coelom as being a cavity many times larger than the pleural portion of the coelom, and this same relative proportion continues throughout all stages investigated, so that when separation of the cavities is completed the pleural cavities are relatively very small in comparison to the pericardial cavity and are situated caudad to it (figs. 16, 17). The further separation of these cavities concerns the closure of the dorsal parietal recesses or pleuroperitoneal canals which are present after the formation of the septum transversum.

In the ten-day embryo the heart has connected with it caudally the omphalomesenteric veins, the umbilical veins, and the ducts of Cuvier. In the reconstruction of the ten-day embryo (fig. 8), through the level of the left pleuropericardial canal, the left duct of Cuvier is seen to pass in the lateral body wall, lateral to the pleuropericardial canal (fig. 8), and then to turn medially to pass to the heart. This lateral constriction of the pleuropericardial canal marks the beginning of the closure of the communication between the two divisions of the coelom. A consideration of the later embryos (figs. 8, 12, 13, $14,15,16,17)$, which illustrate the ducts of Cuvier in their changing relations, shows these vessels to gradually close the pleuropericardial recesses from the lateral to the medial side, and as this process occurs the vessels come to project free into the pericardial coelom. Further study of these figures reveals the fact that these vessels, in closing the pleuropericardial canals, gradually approximate each other and progressively leave the body wall, and it is this gradual approximation which is responsible for the closure of the communications between the cavities. 
With the gradual movement of the ducts of Cuvier from the lateral body wall in a medial direction, the pleuropericardial communication is closed from the lateral to the medial side, as pointed out above. The membrane which is formed in the separation of the cavities has been termed the pleuropericardial membrane and extends from the septum transversum dorsally to the dorsal body wall (figs. 16, 17). The origin of this membrane has been disputed. As pointed out in the literature review, its origin is given in part as coming from the 'lateral mesocardium' (Lockwood, '88) and by a dorsal extension of the septum transversum. The models prepared in this investigation point to the origin as being largely, if not entirely, from the septum transversum.

Other factors were mentioned in the literature review which have been given to account for the closure of the pleuropericardial canal. Uskow ('83) gave three factors which he considered to be of importance: the alteration in position of the foremost part of the lateral mesocardium, the thickening of the 'massa longitudinalis' (tissue alongside of the trachea and oesophagus), and a cell increase in the septum trans. versum. A consideration of these factors in the light of the findings of this investigation shows the conclusions arrived at to agree in the main with the interpretations of Uskow. The change in position of the 'lateral mesocardium' referred to by Uskow is produced by the separation of the ducts of Cuvier from the lateral body wall, and the cell increase in the 'massa transversa' is responsible chiefly for the formation of the pleuropericardial membrane. The reconstructions show the closure to be produced from lateral to the medial side and do not give evidence to the influence of the increase in the 'massa longitudinalis,' as suggested by Uskow.

As previously mentioned, the septum transversum is formed during the ninth day of development (figs. 4, 5) and at this time the pleuropericardial canal is formed. The closure of this communication begins during the tenth day by the processes described above (embryo 8 ) and the pericardial cavity is a closed cavity first in the fourteen-day embryo, and 
not in the early part of the thirteenth day (fig. 14) as pointed out by Lockwood ('88), who described the communication as being largest during the ninth and early part of the tenth days and being closed during the early part of the thirteenth day. This difference may probably be accounted for by the fact that the material employed by Lockwood was possibly not accurately timed.

Mall ('01, '10), in his description of the formation of the diaphragm, described the ventral portion (septum transversum) as receiving its nerve supply while it is opposite the fourth cervical somite, and as it progresses caudalward the nerve (phrenic) is stretched out to reach it. At first this nerve supply reaches the septum transversum through the lateral body wall, passing around the duct of Cuvier, but with the withdrawal of these vessels from the body wall the phrenic nerve alters its position, and in later stages, with the formation of the pleuropericardial membrane, is observed to pass through this membrane to reach the ventral diaphragm (fig. 17).

\section{LITERATURE CITED}

BonNET 1889 Beiträge zur Embryologie der Wiederkäuer, gewonnen am Sehafe. Archiv. fur Anat. und Physiol., S. 1-106.

BoRN 1888 Über die Bildung der Klappen, Ostien, und Scheidewande in Säugetierherzen. Anat. Anzieger, Bd. 3, S. 606-612.

1889 Beiträge zur Entwickelungsgeschichte des Säugetierherzens. Arch. f. mikros. Anat., Bd. 33, S. 284-377.

Brachet 1895 Recherches sur le développement du diaphragme et du foie chez le lapin. Jour. de 1'Anatomie, T. 31, pp. 511-595.

1895 Recherehes sur le développement de la cavité hépato-entérique de l'axolotl, et de l'arrière cavité du péritoine chez les mammifères (lapin). Areh. de Biologie, T. 13, pp. 559-618.

1897 Recherches sur l'évolution de la portion céphalique des cavités pleurales et sur le développement de la membrane pleuro-péricardique. Jour. de l'Anatomie, T. 33, pp. 421-460.

1897 Die Entwickelung der grössen Körperhöhlen und ihre Trennung von einander. Ergebnisse der Anatomie und Entwickelungsgeschichte, Bd. 7, S. 886-936.

HENSEN 1875-1876 Beobachtungen über die Befruchtung und Entwickelung des Kaninchen und Meersehweinchens. Zeitschrift für Anat. und Entwickelungsgeschichte, Bd. 1, S. 213-353. 
Lockwood 1888 Abstract of lectures on development of the organs of circulation and respiration, including the pericardium, diaphragm, and great veins. The British Medical Journal, pp. 731-735.

1889 The early development of the pericardium, diaphragm, and great veins. Philosophical Transactions of the Royal Society, vol. 179, pp. 365-384.

MALL 1891 Development of the lesser peritoneal eavity in birds and mammals. Jour. Morph., vol. 5, pp. 165-179.

1910 Coelom and diaphragm. Keibel and Mall, Human Embryology. Lippineott Co., Philadelphia.

Rosinson 1891-1892 Observations upon the development of the segmentation cavity, the archenteron, the germinal layers and the amnion in mammals. Jour. of Microseopical Science, vol. 33, pp. 369-455.

1896 Studies in the peritoneum; its arrangement in animals. Jour. of Anat. and Physiol., vol. 30, pp. 349-361.

1903 The early stages of the development of the pericardium. Jour. of Anat. and Physiol., vol. 37, pp. 1-17.

STRAHL AND CaRIUS 1889 Beiträge zur Entwickelungsgeschichte des Herzens und der Körperhöhlen. Archiv. für Anat. und Physiol., S. 231-248.

Thompsor 1908 A note on the development of the septum transversum and liver. Jour. of Anat. and Physiol., vol. 42, pp. 170-175.

Uskow 1883 Über die Entwicklung des Zwerchfells, des Pericardiums und des Coeloms. Archiv. für Mikroseopische Anat,, Bd. 22, S. 143-219.

WANG 1917 The earliest stages of development of the blood vessels and of the heart in the ferret embryo. Jour. of Anat., vol. 52, pp. 107-185.

Yoshinaga 1917 A contribution to the early development of the heart in Mammalia, with special reference to the guinea pig. Anat. Rec., vol. 21, pp. 239-308. 